\title{
Combined platinum/perovskite catalyst for an efficient nanostructured air electrode
}

\author{
Doreen Thiele \\ University of Fribourg, Physics Department, Perolles, CH-1700 Fribourg, Switzerland
}

\begin{abstract}
This work shows the stepwise improvement of air electrodes by the right combination of catalysts. In all electrodes carbon nanotubes serve as carbon support. The electrodes are produced by ultrasonic mixing of the carbon nanotubes and the catalysts. Their catalytic activity towards oxygen reduction in alkaline solution is evaluated by polarisation curves and electrochemical impedance spectroscopy. In a first step $\mathrm{La}_{1-\chi} \mathrm{Sr}_{x} \mathrm{MnO}_{3}$ perovskites are investigated, as well as $\mathrm{La}_{0.65} \mathrm{Sr}_{0.35} \mathrm{MnO}_{3}$ and $\mathrm{La}_{0.6} \mathrm{Sr}_{0.4} \mathrm{CoO}_{3}$ are compared. It is found that $\mathrm{La}_{0.65} \mathrm{Sr}_{0.35} \mathrm{MnO}_{3}$ and $\mathrm{La}_{0.6} \mathrm{Sr}_{0.4} \mathrm{CoO}_{3}$ have a positive impact on different parts of the current-potential curve. In a second step the influence of small amounts of platinum as an additional catalyst besides the perovskite is analyzed with the result that platinum lowers significantly the activation polarisation. Finally, the optimum composition of the electrode is found by using the synergetic effect of platinum, $\mathrm{La}_{0.65} \mathrm{Sr}_{0.35} \mathrm{MnO}_{3}$ and $\mathrm{La}_{0.6} \mathrm{Sr}_{0.4} \mathrm{CoO}_{3}$.
\end{abstract}

\section{Introduction}

Fuel cells are a promising technology, because they combine the easy refuelling and the continuous operation of combustion engines as well as the high efficiency and the quiet operation of batteries. But they do not need charging times like batteries and do not cause pollution like combustion engines [1]. Despite of these advantages, up to now the fuel cell could not penetrate the market. Among other things, reasons for that are:

- The loss of efficiency due to high overpotentials.

- Pt, which is the catalyst material used today, gets easily poisoned.

- Pt is expensive, because the Pt reserves are limited.

Therefore, the discovery of new catalyst systems which are more efficient and cheaper than Pt is an important step in the fuel cell development.

In the past other noble metals than Pt, alloys, transition metal oxides (simple oxides, perovskites, spinels, pyrochlors), transition metal chalcogenides and transition metal macrocycles were studied regarding their catalytic activity towards oxygen reduction [2]. But none of them could successfully replace platinum so far.

Norskov et al. [3] demonstrated in a theoretical work that $O$ and $\mathrm{OH}$ binding energies to the catalyst play a crucial role for the catalytic activity of the catalyst. Furthermore, it was shown that Pt

E-mail address: doreen.thiele@unifr.ch. is already a good catalyst, but materials with a somewhat lower oxygen binding energy than Pt should have a higher rate of oxygen reduction [3].

We will concentrate on perovskites in this work. Perovskites have a high oxygen coverage on the surface and a coverage dependent binding energy for oxygen. They can release and take up oxygen in a reversible way [4]. The general formula of perovskites is $\mathrm{ABO}_{3}$, whereby the $\mathrm{B}$ ions are catalytically active $3 \mathrm{~d}$, $4 \mathrm{~d}$ or $5 \mathrm{~d}$ transition metal ions. The valence state of the $B$ ion is varied by partial substitution of the A ion [5]. In 1970, Meadowcroft [6] described the use of perovskites in zinc air batteries for the first time. It was pointed out that doping of $\mathrm{LaCoO}_{3}$ with $\mathrm{Sr}$ increases the electronic conductivity and a catalytic activity towards the oxygen reduction comparable to that of Pt was observed. Studies on many other perovskites followed. Generally, the electrodes were made from the perovskites solely [7-10] or in combination with a carbon support material [11-14]. Partially, the results are controversial; e.g. Manoharan and Shukla [12] found a higher catalytic activity for Coperovskites than for Mn-perovskites, while Karlsson [11] showed it the other way around. It demonstrates the complexity of the issue: the synthesis method of the perovskites, the specific surface area of the perovskite and the support material, the nature of the support material and the preparation method of the electrode have to be considered.

The oxygen reduction reaction takes place at the three phase boundary. The support material should allow a homogenous dispersion of the electrocatalyst on it in order to form a highly reactive large three phase boundary, where catalyst, electrolyte and oxygen contact effectively with each other [2]. Carbon nanotubes are a 
Table 1

Composition of electrodes with one perovskite as catalyst and BET specific surface areas of the different perovskites.

\begin{tabular}{|c|c|c|c|c|}
\hline Nr. & Composition & & & BET $\left[\mathrm{m}^{2} \mathrm{~g}^{-1}\right]$ \\
\hline 1 & 55 wt\% $\left(\mathrm{La}_{0.8} \mathrm{Sr}_{0.2}\right)_{0.98} \mathrm{MnO}_{3}$ & 25 wt\% CNTs & $20 w t \%$ PTFE & 2.06 \\
\hline 2 & $55 \mathrm{wt} \% \mathrm{La}_{0.8} \mathrm{Sr}_{0.2} \mathrm{MnO}_{3}$ & 25 wt\% CNTs & $20 \mathrm{wt} \%$ PTFE & 3.46 \\
\hline 3 & $55 \mathrm{wt} \% \mathrm{La}_{0.65} \mathrm{Sr}_{0.35} \mathrm{MnO}_{3}$ & 25 wt\% CNTs & $20 \mathrm{wt} \%$ PTFE & 9.73 \\
\hline 4 & $55 \mathrm{wt} \% \mathrm{La}_{0.6} \mathrm{Sr}_{0.4} \mathrm{CoO}_{3}$ & $25 \mathrm{wt} \% \mathrm{CNTs}$ & $20 w t \%$ PTFE & 9.89 \\
\hline
\end{tabular}

promising support material as they exhibit a high specific surface, chemical stability and a nanosized pore structure. It was shown that the use of carbon nanotubes leads to a better dispersion of the catalyst on the support, which in turn leads to a better utilisation of the catalyst compared to activated carbons [15-18]. These studies were mainly done with Pt as catalyst. However, in our previous study [19] we demonstrated that carbon nanotubes are also more suitable as support material for perovskites than acetylene black.

In this work we use carbon nanotubes as support material. For the first time, we combine two different perovskites in one electrode, and we investigate the influence of small amounts of Pt as additional catalyst in carbon nanotube/perovskite based air electrodes.

\section{Experimental}

2.1. Materials

The perovskites $\left(\mathrm{La}_{0.6} \mathrm{Sr}_{0.4} \mathrm{CoO}_{3}, \mathrm{La}_{0.65} \mathrm{Sr}_{0.35} \mathrm{MnO}_{3}, \mathrm{La}_{0.8} \mathrm{Sr}_{0.2} \mathrm{MnO}_{3},\left(\mathrm{La}_{0.8} \mathrm{Sr}_{0.2}\right)_{0.98}\right.$ $\mathrm{MnO}_{3}$.) were delivered from Empa, Laboratory for High Performance Ceramics.

The carbon nanotubes (CNTs) were synthesised by fluidized bed chemical vapour deposition on a MgO substrate, impregnated with a Fe nitrate solution, as described elsewhere [20]. In order to obtain carbon nanotubes with a high specific surface area the synthesis temperature was set to $600^{\circ} \mathrm{C}$, the Fe content in the substrate powder was $5 \mathrm{wt} \%$ and acetylene served as carbon source.

For electrodes with Pt, Pt nominally $20 \%$ on carbon black (Aldrich), specified for use as catalyst in fuel cells, was used.

\subsection{Making of the electrodes}

Electrodes with different compositions were produced (Tables 1-3). In general, CNTs, catalysts, PTFE dispersion and distilled water were mixed ultrasonically for $1 \mathrm{~h}$. The mixtures were dried for $18 \mathrm{~h}$ at $60^{\circ} \mathrm{C}$ under air and then heated to $350{ }^{\circ} \mathrm{C}$ for $2 \mathrm{~h}$ to fix the PTFE onto the carbon surface. $0.04 \mathrm{~g}$ of the resulting powder was mixed with $0.16 \mathrm{~g}$ petroleum (Petroleum special, bp $180-220^{\circ} \mathrm{C}$, Fluka) to make a paste, which was spread onto a round piece ( $24 \mathrm{~mm}$ in diameter) of teflonized Toray Carbon Paper TP-090T (QuinTech), serving as gas-diffusion layer. The two layers, catalytic active layer and gas-diffusion layer, were pressed together and heated to $320^{\circ} \mathrm{C}$ for $1 \mathrm{~h}$. And the electrode is finished.

\subsection{Characterisation of the electrodes}

The electrochemical measurements were conducted with a ZAHNER IM6eX electrochemical work station. A three electrode arrangement was chosen: The electrode foil under investigation was pressed against a contact plate in the holder and served as working electrode. The geometric active area of the electrode was $0.785 \mathrm{~cm}^{2}$. The back side (Toray Carbon Paper) was purged with air or oxygen and the catalytic active side was in contact with the electrolyte. The reference electrode was a $\mathrm{Hg} / \mathrm{HgO}$

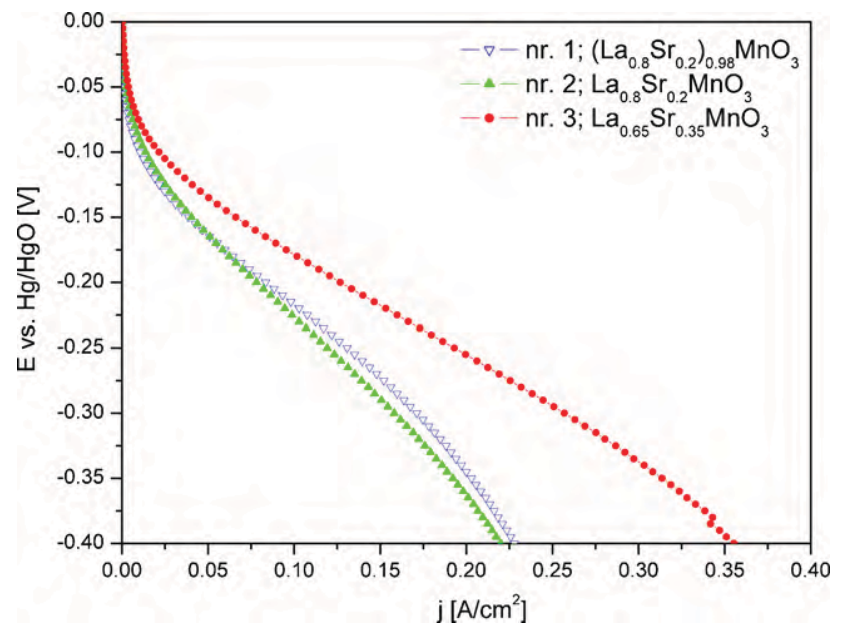

Fig. 1. Steady-state current-potential curves of electrodes with $\mathrm{La}_{1-x} \mathrm{Sr}_{x} \mathrm{MnO}_{3}$ as catalyst, measured with air.

electrode (Radiometer Analytical) in a Haber-Luggin capillary and the counter electrode was a Pt disk (Radiometer Analytical). All measurements were carried out in $6 \mathrm{M} \mathrm{KOH}$ (Aldrich) at room temperature.

Steady-state current-potential curves were measured from -0.4 to $0.8 \mathrm{~V}$ vs. $\mathrm{Hg} / \mathrm{HgO}$.

The electrochemical impedance spectra were recorded in the frequency range from $100 \mathrm{mHz}$ to $100 \mathrm{kHz}$ (single sine). It was measured in the galvanostatic mode, the AC-amplitude was about $10 \%$ of the DC-signal. The obtained spectra were fitted with a least squares fitting program (SIM).

The specific surface area of the CNTs and perovskites were determined by the BET method (Belsorp-Max, Bel Japan).

\section{Results and discussion}

\subsection{Influence of the stoichiometry of the perovskites}

Electrodes composed of carbon nanotubes (CNTs) and $\mathrm{La}_{1-x} \mathrm{Sr}_{x} \mathrm{MnO}_{3}$ were investigated (Table 1, electrode nr. 1-3). The ratio of perovskites to CNTs to PTFE was 11:5:4. Previously it was found, that a higher rate of perovskites to CNTs leads to a higher catalytic activity [19]. Fig. 1 shows the steady-state polarisation curves of the electrodes 1-3 listed in Table 1. Electrode 3 with $\mathrm{La}_{0.65} \mathrm{Sr}_{0.35} \mathrm{MnO}_{3}$ shows the lowest polarisation in

Table 2

Composition of electrodes with one perovskite and Pt on carbon as catalysts and the Pt content of the electrodes.

\begin{tabular}{|c|c|c|c|c|c|}
\hline $\mathrm{Nr}$. & Composition & & & & $\mathrm{mg} \mathrm{Pt} \mathrm{cm}{ }^{-1}$ \\
\hline 5 & $45 \mathrm{wt} \% \mathrm{La}_{0.65} \mathrm{Sr}_{0.35} \mathrm{MnO}_{3}$ & 15 wt $\%$ Pt on carbon & 20 wt $\%$ CNTs & $20 \mathrm{wt} \%$ PTFE & 0.265 \\
\hline 6 & $45 \mathrm{wt} \% \mathrm{La}_{0.6} \mathrm{Sr}_{0.4} \mathrm{CoO}_{3}$ & 15 wt\% Pt on carbon & $20 \mathrm{wt} \%$ CNTs & $20 \mathrm{wt} \%$ PTFE & 0.265 \\
\hline 7 & $50 w t \% \mathrm{La}_{0.6} \mathrm{Sr}_{0.4} \mathrm{CoO}_{3}$ & $10 \mathrm{wt} \%$ Pt on carbon & 20 wt $\%$ CNTs & $20 \mathrm{wt} \%$ PTFE & 0.177 \\
\hline 8 & 55 wt $\% \mathrm{La}_{0.6} \mathrm{Sr}_{0.4} \mathrm{CoO}_{3}$ & 5 wt\% Pt on carbon & 20 wt $\%$ CNTs & 20 wt\% PTFE & 0.088 \\
\hline
\end{tabular}

Table 3

Composition of electrodes with two perovskites and Pt on carbon as catalysts, the Pt content is $0.177 \mathrm{mg} \mathrm{Pt} \mathrm{cm}^{-1}$ in all electrodes.

\begin{tabular}{rllll}
\hline Nr. & Composition & & \\
\hline 9 & $45 w t \% \mathrm{La}_{0.6} \mathrm{Sr}_{0.4} \mathrm{CoO}_{3}$ & $5 w t \% \mathrm{La}_{0.65} \mathrm{Sr}_{0.35} \mathrm{MnO}_{3}$ & 10 wt\% Pt on carbon & 20 wt\% CNTs \\
10 & $40 w t \% \mathrm{La}_{0.6} \mathrm{Sr}_{0.4} \mathrm{CoO}_{3}$ & $10 w t \% \mathrm{La}_{0.65} \mathrm{Sr}_{0.35} \mathrm{MnO}_{3}$ & 10 wt\% Pt on carbon & 20 wt\% PTFE \\
11 & 35 wt\% La $\mathrm{La}_{0.6} \mathrm{Sr}_{0.4} \mathrm{CoO}_{3}$ & 15 wt\% La $\mathrm{La}_{0.65} \mathrm{Sr}_{0.35} \mathrm{MnO}_{3}$ & 10 wt\% Pt on carbon & 20 wt\% PTFE \\
\hline
\end{tabular}




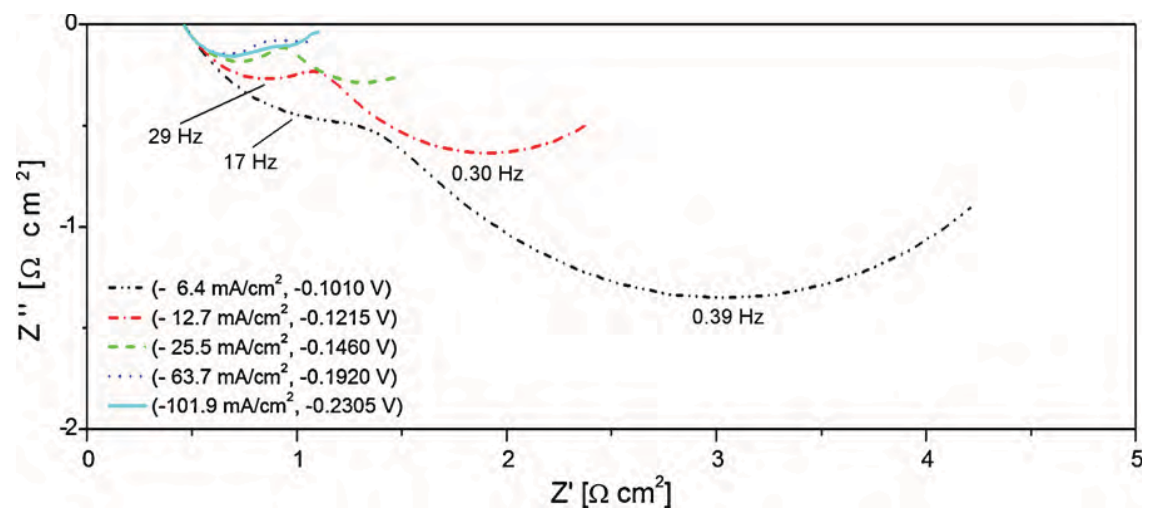

Fig. 2. Nyquist plots of electrode 1: $55 \mathrm{wt} \%\left(\mathrm{La}_{0.8} \mathrm{Sr}_{0.2}\right)_{0.98} \mathrm{MnO}_{3}+25 \mathrm{wt} \% \mathrm{CNTs}$, measured with air.

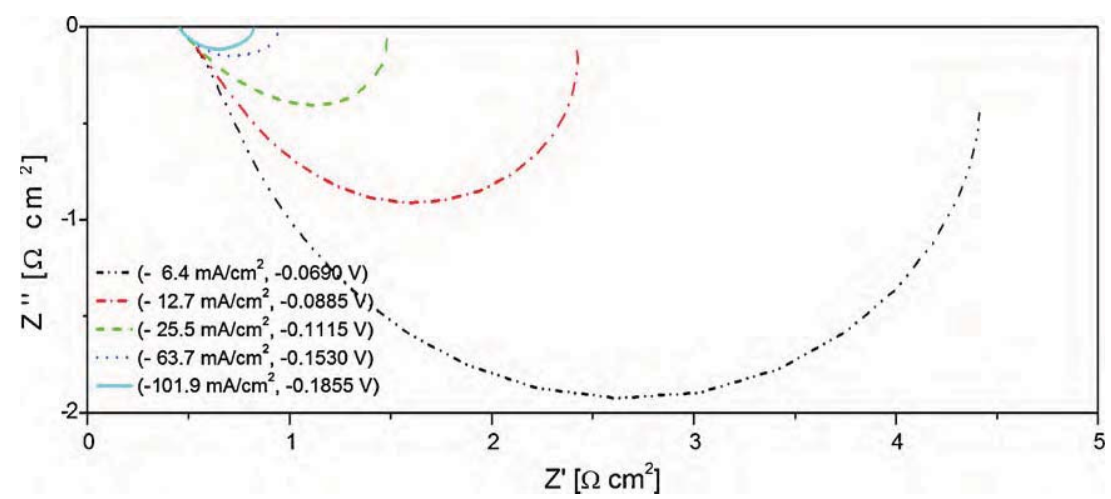

Fig. 3. Nyquist plots of electrode 3: $55 \mathrm{wt} \% \mathrm{La}_{0.65} \mathrm{Sr}_{0.35} \mathrm{MnO}_{3}+25 \mathrm{wt} \% \mathrm{CNTs}$, measured with air.

the whole current region and is therefore the electrode with the highest catalytic activity for the oxygen reduction reaction compared to the electrodes 1 and 2 . This result is in agreement with Matsumoto et al. [7] and Karlsson [11] who also compared different $\mathrm{La}_{1-x} \mathrm{Sr}_{x} \mathrm{MnO}_{3}$ perovskites. Usually the higher catalytic activity of $\mathrm{La}_{1-x} \mathrm{Sr}_{x} \mathrm{MnO}_{3}$ with $x=0.3-0.4$ is explained with the higher electrical conductivity of these perovskites [7]. On the other hand, Manoharan and Shukla [12] discussed that the electrical conductivity of $\mathrm{LaNiO}_{3}$ decreases with increasing $\mathrm{Sr}$ content and showed that $\mathrm{La}_{0.99} \mathrm{Sr}_{0.01} \mathrm{NiO}_{3}$ has a much higher catalytic activity than $\mathrm{LaNiO}_{3}$. This result was explained by the non-stoichiometry of $\mathrm{La}_{0.99} \mathrm{Sr}_{0.01} \mathrm{NiO}_{3}$. Also Kahoul et al. [21] demonstrated on $\mathrm{La}_{1-x} \mathrm{Ca}_{x} \mathrm{CoO}_{3}$ that the perovskite with the highest electrical conductivity displays not necessarily the highest catalytic activity for the oxygen reduction.

In our case another reason for the good performance of $\mathrm{La}_{0.65} \mathrm{Sr}_{0.35} \mathrm{MnO}_{3}$ might be the higher specific surface area compared to $\left(\mathrm{La}_{0.8} \mathrm{Sr}_{0.2}\right)_{0.98} \mathrm{MnO}_{3}$ and $\mathrm{La}_{0.8} \mathrm{Sr}_{0.2} \mathrm{MnO}_{3}$ (Table 1 ). In particular, this might lead to the low concentration polarisation at high current densities. High current densities mean high reaction rates. The oxygen has to be delivered fast to the three phase boundary sites to maintain the reaction. The higher the specific surface area, the more three phase boundary sites are available. Shimizu et al. [13] showed that the higher the specific surface area of a specific perovskite is, the higher the catalytic activity for the oxygen reduction is.

The Nyquist plots of these electrodes display two potentialdependent semi-circles, which decrease with increasing overpotential. When measuring with air, the low frequency semi-circle starts increasing again at high overpotential. This is due to insufficient diffusion of oxygen through the electrolyte film to the catalyst sides and is well described in literature [22,23]. At least two processes, one for each semi-circle are assumed: the low frequency arc is related to diffusion and the high frequency arc to charge transfer. Due to very different time constants of these two processes in the electrode with $\left(\mathrm{La}_{0.8} \mathrm{Sr}_{0.2}\right)_{0.98} \mathrm{MnO}_{3}$, the Nyquist plots of this electrode (Fig. 2) display two clearly distinguishable semicircles. In contrast, the semi-circles are almost merged together in the Nyquist plots of the electrode with $\mathrm{La}_{0.65} \mathrm{Sr}_{0.35} \mathrm{MnO}_{3}$ (Fig. 3), based on comparable time constants for the two ongoing processes. In the electrode with $\mathrm{La}_{0.65} \mathrm{Sr}_{0.35} \mathrm{MnO}_{3}$ the low frequency process (diffusion) is faster and the high frequency process (charge transfer) is slower compared to the electrode with $\left(\mathrm{La}_{0.8} \mathrm{Sr}_{0.2}\right)_{0.98} \mathrm{MnO}_{3}$. This information was extracted from the Bode plots of these electrodes (not shown). The faster diffusion might be explained by the higher specific surface area of $\mathrm{La}_{0.65} \mathrm{Sr}_{0.35} \mathrm{MnO}_{3}$. Oxygen finds faster a three phase boundary site. The slower charge transfer cannot be explained so easily, more detailed investigations on this effect will follow.

The spectra were fitted with the equivalent circuit shown in Fig. 4. The series of two parallel RC elements correspond to the two semi-circles. The resistance $R_{2}$, connected with the high frequency arc, accounts for processes at the catalyst surface (i.e. charge transfer) and the resistance $R_{3}$, connected with the low frequency arc, is related to the electrode morphology (i.e. diffusion processes). $R_{2}$

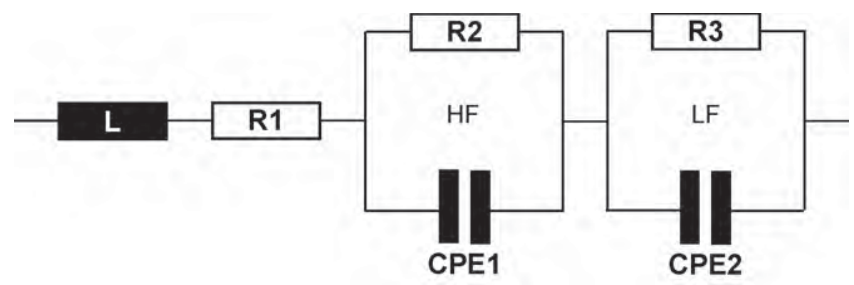

Fig. 4. Equivalent circuit. 
and $R_{3}$ are smallest for electrode 3, leading to their superior performance in the region of activation polarisation and concentration polarisation.

Both semi-circles are slightly compressed; the high frequency arc more than the low frequency arc. Therefore, the capacitances are substituted by constant phase elements. They account for only partially charged double layers. The penetration depth of the current into the pores depends on the frequency. At high frequencies, the current travels only through a part of the pores. That means that only a part of the double layer is charged [25]. The impedance of a constant phase element is given by

$Z_{\mathrm{CPE}}=\frac{1}{C_{\mathrm{CPE}}(j \omega)^{\varphi}}$

where $C_{\mathrm{CPE}}$ is the distributed capacitance and $\varphi$ is a constant, $0<\varphi<1$. When $\varphi=1, \mathrm{C}_{\mathrm{CPE}}$ corresponds to the ideal capacitance $C$. In our case, $\varphi$ of the high frequency loop was about 0.66 , while $\varphi$ of the low frequency loop was about 0.86 .

The resistance $R_{1}$ corresponds to the high frequency intercept with the real axis. It represents the sum of electrolyte resistance, contact resistances and cell resistances. The inductance $L$ stands for the mutual induction occurring at high frequencies, caused by the cable connections.

The most accepted model for gas-diffusion electrodes is the thin-film agglomerate model of Raistrick [26,27]. Catalyst and support form porous aggregates which are flooded with the electrolyte. The catalyst agglomerates are kept together by the Teflon binder, which creates hydrophobic gas channels. As current is drawn from the electrode, reactant gas diffuses through the channels, dissolves in the film surrounding the agglomerates and, after diffusing a certain distance, reacts on the three phase boundary. According to this model 3 semi-circles should be observed in the Nyquist plot of porous gas-diffusion electrodes; one high frequency arc related to charge transfer processes, one mid-frequency arc related to agglomerate diffusion and one low frequency arc related to diffusion of oxygen through the thin electrolyte film. But this was never observed. The theoretical work of Bultel et al. [28] shows by numerical simulations of original models how, depending on the capacitance and other parameters, one potential-dependent arc splits in two arcs, whereby the low frequency arc is related to diffusion and the high frequency arc is related to charge transfer. Paganin et al. [23], Fischer et al. [24], Huang et al. [27] reported about one high frequency potential-independent loop and one low frequency potential-dependent loop. The potential-independent loop is ascribed to distributed resistances inside the catalyst layer. The potential-dependent arc contains information about charge transfer processes, agglomerate diffusion and diffusion through the thin film.

\subsection{Influence of the perovskite composition}

Electrodes with the perovskites $\mathrm{La}_{0.65} \mathrm{Sr}_{0.35} \mathrm{MnO}_{3}$ (electrode $\mathrm{nr}$. 3, Table 1) and $\mathrm{La}_{0.6} \mathrm{Sr}_{0.4} \mathrm{CoO}_{3}$ (electrode nr. 4, Table 1 ) were compared (Fig. 5). Although both perovskites have about the same specific surface area, the electrode with $\mathrm{La}_{0.65} \mathrm{Sr}_{0.35} \mathrm{MnO}_{3}$ shows a remarkably lower concentration polarisation. But the electrode with $\mathrm{La}_{0.6} \mathrm{Sr}_{0.4} \mathrm{CoO}_{3}$ shows a slightly lower activation polarisation. $\mathrm{La}_{0.65} \mathrm{Sr}_{0.35} \mathrm{MnO}_{3}$ and $\mathrm{La}_{0.6} \mathrm{Sr}_{0.4} \mathrm{CoO}_{3}$ have a positive impact on different parts of the current-potential curve. Shimizu et al. [13] investigated Ca-substituted Co- and Mn-perovskites. He found in contradiction to our findings that Co-perovskites are always more active than Mn-perovskites. Manoharan and Shukla [12] found as well a higher catalytic activity for $\mathrm{La}_{0.5} \mathrm{Sr}_{0.5} \mathrm{CoO}_{3}$ than for $\mathrm{La}_{0.7} \mathrm{Sr}_{0.3} \mathrm{MnO}_{3}$. But Karlsson [11] stated that only Mn-perovskites are suitable for gas-diffusion electrodes, because $\mathrm{Co}$ - and $\mathrm{Ni}$ perovskites lack both for activity and stability.

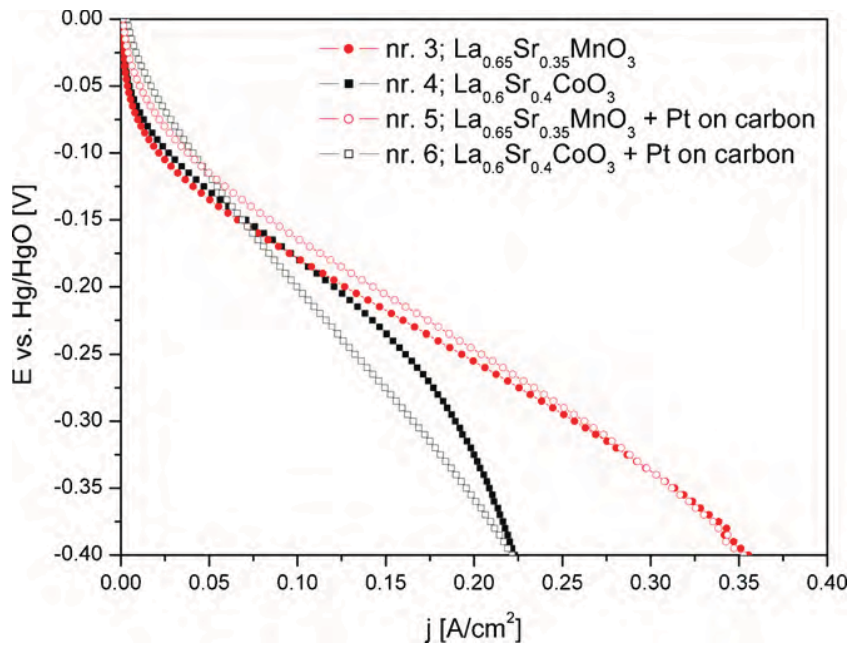

Fig. 5. Steady-state current-potential curves of electrodes, containing $\mathrm{La}_{0.65} \mathrm{Sr}_{0.35} \mathrm{MnO}_{3}$ or $\mathrm{La}_{0.6} \mathrm{Sr}_{0.4} \mathrm{CoO}_{3}$ in comparison to electrodes containing the perovskite and platinum on carbon, measured with air.

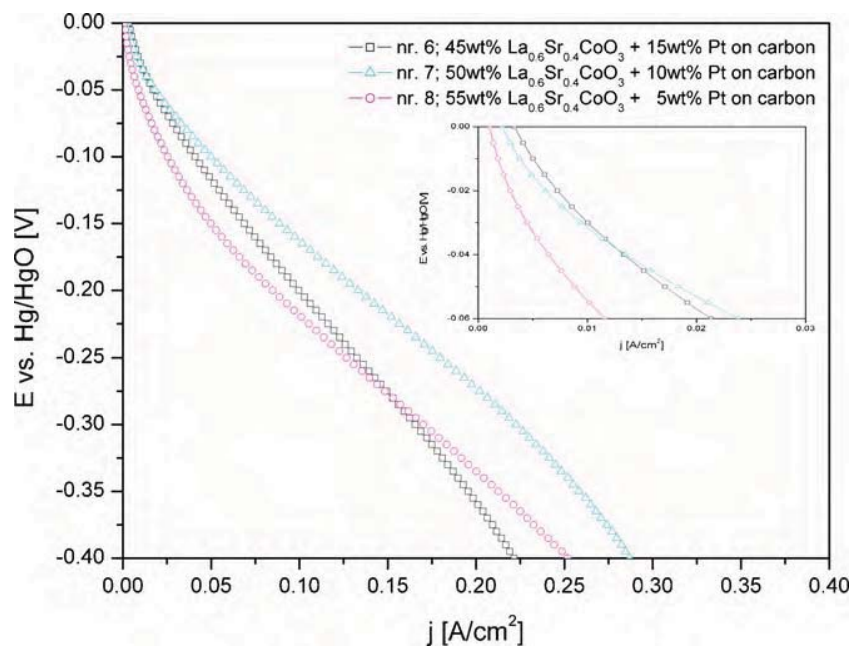

Fig. 6. Steady-state current-potential curves of electrodes, containing $\mathrm{La}_{0.6} \mathrm{Sr}_{0.4} \mathrm{CoO}_{3}$ and Pt on carbon in different amounts, measured with air.

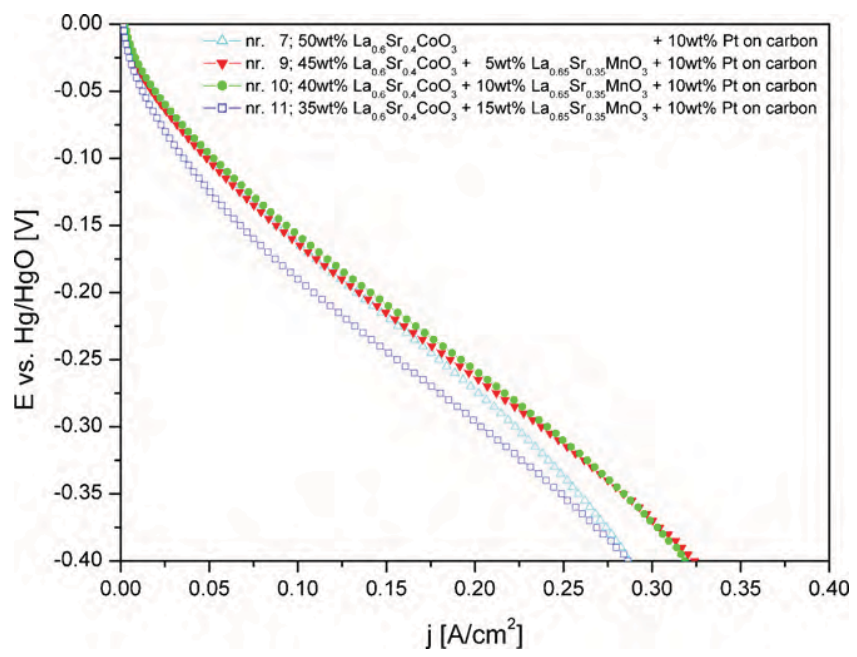

Fig. 7. Steady-state current-potential curves of electrodes, containing $\mathrm{La}_{0.6} \mathrm{Sr}_{0.4} \mathrm{CoO}_{3}$ and $\mathrm{La}_{0.65} \mathrm{Sr}_{0.35} \mathrm{MnO}_{3}$ in different amounts and $\mathrm{Pt}$ on carbon, measured with air. 


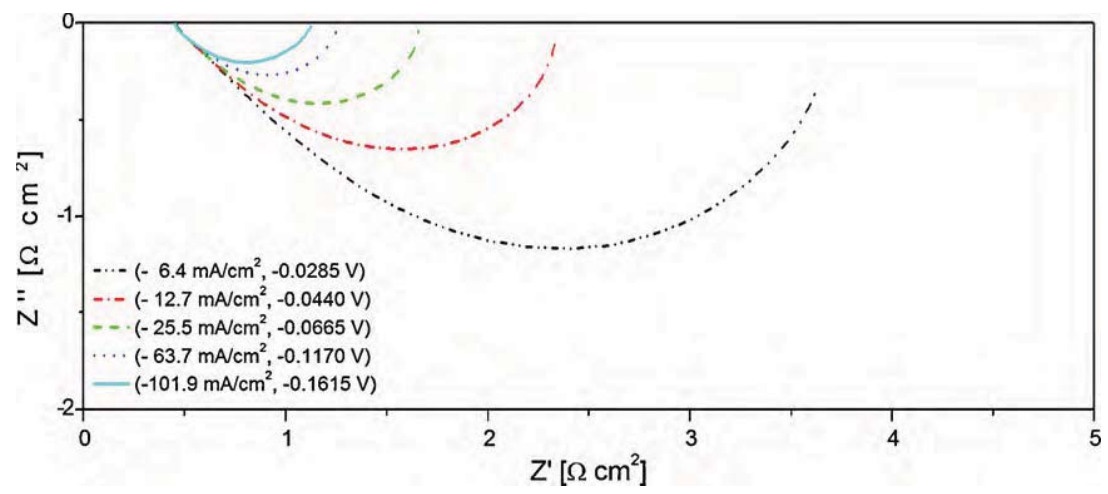

Fig. 8. Nyquist plots of electrode 10: $40 \mathrm{wt} \% \mathrm{La}_{0.6} \mathrm{Sr}_{0.4} \mathrm{CoO}_{\mathrm{s}}+10 \mathrm{wt} \% \mathrm{La}_{0.65} \mathrm{Sr}_{0.35} \mathrm{MnO}_{3}+10 \mathrm{wt} \% \mathrm{Pt}$ on carbon +20 wt $\% \mathrm{CNTs}$, measured with air.

The Nyquist plots of these two electrodes look very similar. At low overpotentials both resistances $R_{2}$ and $R_{3}$ are slightly lower for the electrode with $\mathrm{La}_{0.6} \mathrm{Sr}_{0.4} \mathrm{CoO}_{3}$, contributing to the low activation polarisation. At high overpotentials both resistances $R_{2}$ and $R_{3}$ are slightly lower for the electrode with $\mathrm{La}_{0.65} \mathrm{Sr}_{0.35} \mathrm{MnO}_{3}$, contributing to the low concentration polarisation.

\subsection{Influence of the Pt addition}

In the next step Pt on carbon was added to the electrode mixtures (Table 2). Fig. 5 shows that the addition of $15 \mathrm{wt} \% \mathrm{Pt}$, which corresponds to a Pt content of $0.265 \mathrm{mg} \mathrm{Pt} \mathrm{cm}^{-1}$, leads to a significant lowering of the activation polarisation compared to the electrodes without Pt.

The analysis of the Nyquist plots was also done with the equivalent circuit shown in Fig. 4. The resistance $R_{2}$ of the electrodes with platinum is significant lower, especially at low current densities, which contributes to the lower activation polarisation with platinum. The resistance $R_{3}$ of the electrodes with platinum is slightly lower at low overpotentials, and slightly higher at high overpotentials compared to the electrodes without platinum.

Fig. 6 shows the polarisation curves of electrodes, composed of different amounts of $\mathrm{La}_{0.6} \mathrm{Sr}_{0.4} \mathrm{CoO}_{3}$ and Pt on carbon, measured with air. In the inset of Fig. 6 it can be seen that in the region of activation polarisation the electrode with the highest content of Pt $\left(0.265 \mathrm{mg} \mathrm{Pt} \mathrm{cm}^{-1}\right)$ shows the best performance and the one with the lowest Pt content $\left(0.088 \mathrm{mg} \mathrm{Pt} \mathrm{cm}^{-1}\right)$ the worst performance. But at high overpotentials the electrode with $10 \mathrm{wt} \% \mathrm{Pt}$ on carbon (electrode nr. 7), which corresponds to a Pt content of $0.177 \mathrm{mg} \mathrm{Pt} \mathrm{cm}^{-1}$, becomes the best electrode, while the electrode with the highest Pt content becomes the worst electrode, because of insufficient delivery of oxygen to the three phase boundary sites. When measuring with pure oxygen (not shown), the electrode with the highest Pt content shows the best performance in the whole current region.

\subsection{Optimized amounts of perovskites and Pt}

Due to the fact that $\mathrm{La}_{0.65} \mathrm{Sr}_{0.35} \mathrm{MnO}_{3}$ lowers the concentration polarisation and $\mathrm{La}_{0.6} \mathrm{Sr}_{0.4} \mathrm{CoO}_{3}$ has a positive impact on the activation polarisation and $\mathrm{Pt}$ on carbon reduces the activation polarisation further, electrodes were composed of $\mathrm{La}_{0.65} \mathrm{Sr}_{0.35} \mathrm{MnO}_{3}$ and $\mathrm{La}_{0.6} \mathrm{Sr}_{0.4} \mathrm{CoO}_{3}$ and Pt on carbon. In Fig. 7 it can be seen that a $\mathrm{La}_{0.65} \mathrm{Sr}_{0.35} \mathrm{MnO}_{3}$ content of $5-10 \mathrm{wt} \%$ leads to a remarkable reduction of the concentration polarisation compared to the electrode which contains only $\mathrm{La}_{0.6} \mathrm{Sr}_{0.4} \mathrm{CoO}_{3}$ and $\mathrm{Pt}$ on carbon as catalysts. When the $\mathrm{La}_{0.65} \mathrm{Sr}_{0.35} \mathrm{MnO}_{3}$ amount in the electrode is increased to $15 \mathrm{wt} \%$ or even more, the activation polarisation increases.
Fig. 8 shows the Nyquist plot of electrode 10, composed of 40 wt\% $\mathrm{La}_{0.6} \mathrm{Sr}_{0.4} \mathrm{CoO}_{\mathrm{s}}, 10 \mathrm{wt} \% \mathrm{La}_{0.65} \mathrm{Sr}_{0.35} \mathrm{MnO}_{3}, 10 \mathrm{wt} \%$ Pt on carbon, 20 wt $\%$ CNTs and 20 wt\% PTFE. The spectrum was also fitted with the equivalent circuit shown in Fig. 4. The resistances $R_{2}$ and $R_{3}$ were the lowest at all overpotentials compared to the resistances of the other electrodes under investigation. Electrode 10 was the best electrode.

Gustavsson et al. [29] and Trogadas and Ramani [30] also showed that the combination of Pt with metal oxides can increase the catalytic activity towards the oxygen reduction. Gustavsson et al. [29] used a $\mathrm{TiO}_{2}$ layer between platinum and Nafion. The better performance of this arrangement was attributed to a better dispersion of $\mathrm{Pt}$ on $\mathrm{TiO}_{2}$ compared to Nafion and in addition, substantial proton conduction through the thin $\mathrm{TiO}_{2}$ layer. Trogadas and Ramani [30] demonstrated that a $\mathrm{Pt} / \mathrm{C} / \mathrm{MnO}_{2}$ hybrid catalyst leads to $50 \%$ less production of hydrogen peroxide compared to $\mathrm{Pt} / \mathrm{C}$.

\section{Conclusions}

Air electrodes based on carbon nanotubes, different perovskites and Pt as additional catalyst were electrochemically investigated regarding their catalytic activity towards the oxygen reduction reaction. It was found that $\mathrm{La}_{0.65} \mathrm{Sr}_{0.35} \mathrm{MnO}_{3}$ leads to a low concentration polarisation and $\mathrm{La}_{0.6} \mathrm{Sr}_{0.4} \mathrm{CoO}_{3}$ to a low activation polarisation. The addition of Pt is necessary to lower the activation polarisation further. The best electrode had the following composition: $40 \mathrm{wt} \% \mathrm{La}_{0.6} \mathrm{Sr}_{0.4} \mathrm{CoO}_{3}+10 \mathrm{wt} \% \mathrm{La}_{0.65} \mathrm{Sr}_{0.35} \mathrm{MnO}_{3}+10 \mathrm{wt} \% \mathrm{Pt}$ on carbon $+20 w t \%$ CNTs $+20 w t \%$ PTFE. $10 w t \%$ Pt on carbon corresponds to a Pt content of $0.177 \mathrm{mg} \mathrm{Pt} \mathrm{cm}^{-1}$.

It might be possible to minimize the usage of Pt further by using the synergetic effect of different perovskites. And with that further material cost reductions would be possible. The described process of electrode fabrication is an easy, up scalable process.

\section{References}

[1] D.S. Cameron, Platinum Met. Rev. 22 (1978) 38.

[2] B. Viswanathan, C. Venkateswara Rao, U.V. Varadaraju, Photo/Electrochemistry \& Photobiology in the Environment, Energy and Fuel, Research Signpost, 2006 p. 43.

[3] J.K. Norskov, J. Rossmeisl, A. Logadottir, L. Lindqvist, J.R. Kitchin, T. Bligaard, H. Jonsson, J. Phys. Chem. B 108 (2004) 17886

4] A. Weidenkaff, Adv. Eng. Mater. 6 (2004) 709

[5] R.J.H. Voorhoeve, D.W. Johnson, J.P. Remeika, P.K. Gallagher, Science 195 (1977) 827.

[6] D.B. Meadowcroft, Nature 226 (1970) 847

[7] Y. Matsumoto, H. Yoneyama, H. Tamura, J. Electroanal. Chem. 83 (1977) 237.

[8] T. Kudo, H. Obayashi, M. Yoshida, J. Electrochem. Soc. 124 (1977) 321.

[9] F.R. van Buren, G.H.J. Broers, C. Boesveld, A.J. Bouman, J. Electroanal. Chem. 87 (1978) 381.

[10] G. Bronoel, J.C. Grenier, J. Reby, Electrochim. Acta 25 (1980) 1015.

[11] G. Karlsson, Electrochim. Acta 30 (1985) 1555.

[12] R. Manoharan, A.K. Shukla, Electrochim. Acta 30 (1985) 205. 
[13] Y. Shimizu, K. Uemura, H. Matsudo, N. Miura, N. Yamazoe, J. Electrochem. Soc. 137 (1990) 3430.

[14] H. Arai, S. Müller, O. Haas, J. Electrochem. Soc. 147 (2000) 3584

[15] F. Yuan, H. Ryu, Nanotechnology 15 (2004) S596.

[16] T. Matsumoto, T. Komatsu, K. Arai, T. Yamazaki, M. Kijima, H. Shimizu, Y. Takasawa, J. Nakamura, Chem. Commun. (2004) 840.

[17] H. Tang, J.H. Chen, Z.P. Huang, D.Z. Wang, Z.F. Ren, L.H. Nie, Y.F. Kuang, S.Z. Yao, Carbon 42 (2004) 191.

[18] D. Guo, H. Li, J. Electroanal. Chem. 573 (2004) 197.

[19] D. Thiele, A. Zuettel, J. Power Sources 183 (2008) 590.

[20] P. Mauron, C. Emmenegger, P. Sudan, P. Wenger, S. Rentsch, A. Züttel, in: T.S. Srivatsan, R.A. Varin (Eds.), Processing and Fabrication of Advanced Materials XI, ASM International, Columbus, OH, USA, 2003, p. 93.

[21] A. Kahoul, A. Hammouche, F. Naamoune, P. Chartier, G. Poillerat, J.F. Koenig, Mater. Res. Bull. 35 (2000) 1955.
[22] J. Perez, E.R. Gonzalez, E.A. Ticianelli, Electrochim. Acta 44 (1998) 1329.

[23] V.A. Paganin, C.L.F. Oliveira, E.A. Ticianelli, T.E. Springer, E.R. Gonzalez, Electrochim. Acta 43 (1998) 3761.

[24] A. Fischer, J. Jindra, H. Wendt, J. Appl. Electrochem. 28 (1998) 277.

[25] I.D. Raistrick, Electrochim. Acta 35 (1990) 1579.

[26] T.E. Springer, I.D. Raistrick, J. Electrochem. Soc. 136 (1989) 1594.

[27] H. Huang, W. Zhang, M. Li, Y. Gan, J. Chen, Y. Kuang, J. Coll. Interf. Sci. 284 (2005)

[28] Y. Bultel, L. Genies, O. Antoine, P. Ozil, R. Durand, J. Electroanal. Chem. 527 (2002) 143.

[29] M. Gustavsson, H. Ekström, P. Hanarp, L. Eurenius, G. Lindbergh, B. Kasemo, J. Power Sources 163 (2007) 671.

[30] P. Trogadas, V. Ramani, J. Power Sources 174 (2007) 159. 